\title{
Extracellular cadmium in the bronchoalveolar space of long-term tobacco smokers with and without COPD and its association with inflammation
}

This article was published in the following Dove Press journal:

International Journal of COPD

II May 2016

Number of times this article has been viewed

\author{
Britt-Marie Sundblad ${ }^{1} *$ \\ Jie Jil,* \\ Bettina Levänen' \\ Klara Midander ${ }^{2}$ \\ Anneli Julander ${ }^{2}$ \\ Kjell Larsson' \\ Lena Palmberg' \\ Anders Lindén'
}

'Unit for Lung and Airway Research, ${ }^{2}$ Unit for Occupational and

Environmental Dermatology, Institute of Environmental Medicine, Karolinska Institutet, Stockholm, Sweden

*These authors contributed equally to this work
Correspondence: Anders Lindén Unit for Lung and Airway Research, Institute of Environmental Medicine, Karolinska Institutet, PO Box 210 SE-17I 77 Stockholm, Sweden Tel +46852482217 Email anders.linden@ki.se

\begin{abstract}
Tobacco contains cadmium, and this metal has been attributed a causative role in pulmonary emphysema among smokers, although extracellular cadmium has not to date been quantified in the bronchoalveolar space of tobacco smokers with or without COPD. We determined whether cadmium is enhanced in the bronchoalveolar space of long-term tobacco smokers with or without COPD in vivo, its association with inflammation, and its effect on chemokine release in macrophage-like cells in vitro. Bronchoalveolar lavage (BAL), sputum, and blood samples were collected from current, long-term smokers with and without COPD and from healthy nonsmokers. Cadmium concentrations were determined in cell-free BAL fluid using inductively coupled plasma mass spectrometry. Blood monocyte-derived macrophages were exposed to cadmium chloride in vitro. Depending upon the type of sample, molecular markers of inflammation were quantified either as protein (enzyme-linked immunosorbent assay) or as mRNA (real-time polymerase chain reaction). Cadmium concentrations were markedly increased in cell-free BAL fluid of smokers compared to that of nonsmokers ( $\mathrm{n}=19-29 ; P<0.001)$, irrespective of COPD. In these smokers, the measured cadmium displayed positive correlations with macrophage TNF- $\alpha$ mRNA in BAL, neutrophil and $\mathrm{CD} 8^{+}$cell concentrations in blood, and finally with IL-6, IL-8, and MMP-9 protein in sputum $(\mathrm{n}=10-20 ; P<0.05)$. The cadmium chloride exposure caused a concentration-dependent increase in extracellular IL- 8 protein in monocyte-derived macrophages in vitro. In conclusion, extracellular cadmium is enhanced in the bronchoalveolar space of longterm smokers and displays pro-inflammatory features. Its pathogenic role in tobacco-induced disease deserves further evaluation.
\end{abstract}

Keywords: cigarette, metal, obstruction, macrophage, neutrophil

\section{Introduction}

The metal cadmium is present in tobacco and therefore also in cigarettes. ${ }^{1-3}$ However, it is known that the content of cadmium in tobacco varies markedly depending on both brand and country of origin, even though the average cadmium content in cigarettes is always substantial $(0.5-1.6 \mu \mathrm{g} / \mathrm{g}){ }^{4,5}$ Importantly, cadmium exposure is toxic to several mammalian organs and has been associated with pulmonary emphysema in tobacco smokers, ${ }^{6}$ in whom elevated cadmium concentrations have been detected in body fat, blood, urine, and amniotic fluid, thereby indicating systemic absorption, presumably via the lungs. ${ }^{7}$ Tentatively, cadmium is a metal that bears the potential to constitute a pathogenic factor in tobacco smokers.

There is to date limited information published on cadmium concentrations in the lungs of human tobacco smokers. Some studies on lung tissue from lung cancer patients have showed the presence of cadmium, ${ }^{8,9}$ and in one study, extracellular 
cadmium concentrations were measured in bronchoalveolar lavage (BAL) samples from patients with interstitial lung diseases. ${ }^{10}$ Notably, this particular study suggested that extracellular cadmium can be detected in the bronchoalveolar space of humans. Finally, cadmium concentrations in exhaled breath condensate from smokers with or without COPD have been shown to be higher than in nonsmokers, a finding which is compatible with, although not a conclusive evidence of, increased cadmium in the bronchoalveolar space of smokers. ${ }^{11}$

In terms of mechanistic actions of cadmium in animal lung models, there is limited published information as well. Inhalation of cadmium chloride $\left(\mathrm{CdCl}_{2}\right)$ in dogs induced a transient neutrophil accumulation and an increased bronchial responsiveness to histamine which was reversible. ${ }^{12}$ In a rat model, repeated local administration of $\mathrm{CdCl}_{2}$ induced an accumulation of both macrophages and neutrophils, as well as signs of emphysema. ${ }^{13}$ Thus, cadmium is a candidate for being a pathogenic factor involved in excess mobilization of innate effector cells, tissue destruction and functional alterations, as judged from these animal models.

Until date, there is no published information on local extracellular concentrations of cadmium in the bronchoalveolar space of human tobacco smokers with and without COPD, nor in relation to markers of inflammation. Given this and what is known about the pathogenic potential and impact on innate effector cells, referred earlier, we hypothesized that extracellular cadmium concentrations are enhanced in the bronchoalveolar space of tobacco smokers and that these enhanced cadmium concentrations are associated with markers of inflammation relating to innate effector cells. The main aim of the current study was to evaluate this hypothesis and to investigate how cadmium concentrations relate to COPD. To do this, we examined BAL, blood, and sputum samples from current, long-term cigarette smokers with and without mild-to-severe COPD, and from healthy nonsmokers. We also assessed the potential of cadmium to be directly involved in the mobilization of innate effector cells by examining its effect on chemokine release in human macrophage-like cells in vitro.

\section{Materials and methods Study design}

\section{Ethics}

The study protocol was ethically reviewed and approved by the Regional Ethics Committee in Stockholm, Sweden (Diary No 2005/733-31/1-4), and the study was conducted in accordance with the Declaration of Helsinki.

\section{Recruitment}

The study subjects were recruited through advertisement in the daily press and via the outpatient clinic at the Lung Allergy Clinic, Karolinska University Hospital. All participating subjects were recruited after oral and written informed consent, and their personal information was anonymized. This was also the case for the donors of blood leukocytes.

\section{Study subjects}

Our cohort included current smokers $(n=57)$ as well as healthy nonsmokers $(n=23) .{ }^{14}$ Subjects had no asthma, allergy, or other pulmonary diseases, and denied heart diseases or other clinically significant diseases. Among the current smokers, those with a post-bronchodilator forced expiratory volume in 1 second $\left(\mathrm{FEV}_{1}\right) /$ forced vital capacity $(\mathrm{FVC})<0.7$ and an $\mathrm{FEV}_{1} 39 \%-98 \%$ of predicted value constituted the COPD group $(n=28)$ and smokers with a post-bronchodilator $\mathrm{FEV}_{1} / \mathrm{FVC}>0.7$ and an $\mathrm{FEV}_{1}>70 \%$ of predicted value constituted the non-COPD group $(n=29)$. Smoking was not allowed the last hour preceding the investigations.

For the measurement of extracellular cadmium concentrations in the bronchoalveolar space, we harvested and investigated BAL samples from 12 long-term smokers with COPD, 17 long-term smokers without COPD, and 19 healthy nonsmokers (clinical characteristics in Table 1). For the evaluation of correlations between extracellular cadmium concentrations and different cellular and molecular markers of innate effector cells, the number of available samples varied, and the actual $\mathrm{n}$ is stated for each analysis.

The study subjects underwent clinical examination, spirometry and bronchoscopy with the collection of BAL fluid, as previously described. ${ }^{14-16}$ Likewise, samples of induced sputum and blood were collected, as previously described. ${ }^{16}$

\section{Handling of BAL and sputum samples}

The BAL samples were subjected to Cytospin ${ }^{\circledR}$ centrifugation, and cell differential counts were determined (Table 1) from slides stained with May-Grünwald Giemsa. Cell-free BAL fluid samples were collected after centrifugation and frozen $\left(-80^{\circ} \mathrm{C}\right)$ for subsequent analyses. ${ }^{16}$ For each induced sputum sample, an equal volume of dithiothreitol (0.1\%) was added to the whole-sputum sample, whereafter the sample was rocked in a water bath $\left(15-20\right.$ minutes, at $\left.37^{\circ} \mathrm{C}\right)$, and then filtered and centrifuged. Cell-free sputum was then collected from the supernatant and stored $\left(-80^{\circ} \mathrm{C}\right)$ for subsequent analyses. Some of the basal results in this study have been included in previous publications, ${ }^{14-16}$ however, 
Table I Characteristics of the groups of the study cohort

\begin{tabular}{|c|c|c|c|}
\hline Clinical information & Smokers with COPD & Smokers without COPD & Nonsmokers \\
\hline Number & 12 & 17 & 19 \\
\hline Sex, male/female & $5 / 7$ & $8 / 9$ & $13 / 6$ \\
\hline Smoking (range) (pack years) & $40(20-60)$ & $35(5-60)$ & 0 \\
\hline Age (range) (years) & $61.5(48-73)^{*}$ & $53(4 I-65)$ & $54(4 I-72)$ \\
\hline $\mathrm{FEV}_{1}$ (range) (L) & $1.81(0.94-3.77)^{* * * \ldots \#}$ & $3.10(2.03-4.96)$ & $3.70(2.4 I-4.76)$ \\
\hline $\mathrm{FEV}_{1}$ (range) (\%pred) & $59(39-98)^{* * * \ldots \ldots+1}$ & $93(80-119)$ & $10 \mid(74-125)$ \\
\hline FVC (range) (L) & $3.28(1.6-5.8 I)^{*}$ & $4.26(2.67-6.72)$ & $4.36(2.79-6.30)$ \\
\hline FVC (range) (\%pred) & $85(59-113)^{*}$ & $92(75-116)$ & $93(78-124)$ \\
\hline $\mathrm{FEV}_{1} / \mathrm{FVC}$ (range) (\%) & $57(45-65)^{* * * \ldots+\#}$ & $76(7 \mid-88)$ & $81(73-91)$ \\
\hline $\mathrm{DL}_{\mathrm{cO}}$ (range) $\left(\mathrm{mL} \mathrm{min}^{-1}\right)$ & I $3.3(6.46-22.7) * * * \ldots \#$ & $19.8(11.7-26.6)^{*}$ & $25.4(17.5-33.0)$ \\
\hline $\mathrm{DL}_{\mathrm{co}}$ (range) (\%pred) & $51(27-78)^{* * * * \ldots}$ & $74(50-90)^{* *}$ & $90(67-109)$ \\
\hline \multicolumn{4}{|l|}{ BAL fluid (range) ( $10^{3}$ cells $\left./ \mathrm{mL}\right)$} \\
\hline Total cells & $237(100-1,283)^{* *}$ & $342(118-1,196)^{* * *}$ & $122(53-172)$ \\
\hline Neutrophils & $9(2-24)^{* *}$ & $6(I-27)^{* * *}$ & $2(0-22)$ \\
\hline Macrophages & $205(80-1,039)^{* *}$ & $307(107-1,083)^{*}$ & $91(47-149)$ \\
\hline Lymphocytes & $12(0-192)$ & II (4-79) & $5(0-40)$ \\
\hline Basophils & $0(0-7)$ & $0(0-1)$ & 0 \\
\hline Eosinophils & $2(0-30) * * *, \#$ & $0(0-7)$ & $0(0-4)$ \\
\hline
\end{tabular}

Notes: Data are presented as median (range). Comparison between smokers with COPD and healthy nonsmokers: $* P<0.05$, $* * P<0.0$ I, and $* * * P<0.00$ I; comparison between smokers with COPD and smokers without COPD: $\# P<0.05, \# P<0.0$ I, and ${ }^{\#} P<0.00$ I.

Abbreviations: $\mathrm{DL}_{\mathrm{co}}$, diffusion capacity; $\mathrm{FEV}_{1}$, forced expiratory volume in I second; FVC, forced vital capacity; BAL, bronchoalveolar lavage.

they were used in different constellations and interpreted in unique contexts.

\section{Cadmium in cell-free BAL samples}

The cadmium concentrations in cell-free BAL samples were determined utilizing an inductively coupled plasma mass spectrometry instrument (Thermo X series II; Thermo Fisher Scientific, Waltham, MA, USA) equipped with a collision/ reaction cell system. This analysis of extracellular cadmium was performed according to the standard of SS-EN ISO 17294-2 (Water quality - Application of inductively coupled plasma mass spectrometry [ICP-MS] - Part 2: Determination of 62 elements) at Stockholm University, Sweden (ISOcertified laboratory).

The isotope ${ }^{114} \mathrm{Cd}$ was utilized for the detection of cadmium concentrations in our cell-free BAL fluid samples. We chose this isotope instead of ${ }^{111} \mathrm{Cd}$ because in samples with low cadmium concentrations, ${ }^{114} \mathrm{Cd}$ has higher abundance compared to that of the ${ }^{111} \mathrm{Cd}$. Any possible interference of the ${ }^{114} \mathrm{Sn}$ was avoided by the measurement of this particular isotope and adjusting for its presence using the instrument software.

Rhodium $\left({ }^{103} \mathrm{Rh}\right)$ was used for recovery calculations. The limit of detection (LOD) was set to $0.01 \mu \mathrm{g} / \mathrm{L}$ for cadmium using $3 \times$ standard deviation (SD) in blank samples. The relative SD was consistently $<20 \%$ in the samples.

In addition to the cadmium analysis described earlier, we attempted to assess background exposure to automotive particulate pollution with nanoparticles by analyzing our BAL samples for palladium. ${ }^{17}$

\section{In vitro experiments on macrophage- like cells}

\section{Cell isolation}

Peripheral blood mononuclear cells (PBMCs) were isolated from the buffy coat (Karolinska University Hospital) of five healthy human donors ( $\mathrm{n}=5$ ) utilizing standard density gradient centrifugation on Ficoll-Paque ${ }^{\text {TM }}$ PLUS (GE Healthcare Life Science, Little Chalfont, Buckinghamshire, UK) in accordance with the manufacturer's instructions. Each donor yielded $\sim 1 \times 10^{9}$ PBMCs, and we seeded these PBMCs (15 million cells/well) into six-well tissue culture plates (BD Biosciences, San Jose, CA, USA), thereby obtaining 5.76 \pm 2.4 million cells/well (mean $\pm \mathrm{SD}$ ) after exposure. To establish macrophage-like cells (ie, monocyte-derived macrophages), we first cultured PBMCs with Iscove's modified Dulbecco's medium (IMDM; Thermo Fisher Scientific) supplemented with 4-(2-hydroxyethyl)1-piperazineethanesulfonic acid (HEPES; $10 \mathrm{mM}$; Thermo Fisher Scientific) and penicillin-streptomycin antibiotics (PEST; Lonza Group, Basel, Switzerland). They were incubated $\left(5 \% \mathrm{CO}_{2}, 2\right.$ hours at $\left.37^{\circ} \mathrm{C}\right)$, and then the nonadhered cells were washed away using phosphate-buffered saline. The adhered cells were cultured during 7 days with supplemented IMDM (10\% of heat-inactivated pooled human serum from Fisher Scientific GTF AB [Lund, Sweden] plus $10 \mathrm{mM}$ of HEPES and PEST). The media were replaced every third day. 
The obtained macrophage-like cells had a high purity $(88 \%$, $\mathrm{n}=5$ ), as determined by flow cytometry (BD LSRFortessa ${ }^{\mathrm{TM}}$ ) targeting archetype surface antigens $\left(\mathrm{CD} 14^{+}, \mathrm{CD} 68^{+}\right)$. The cell viability, as assessed using exclusion of trypan blue dye both prior to and after the in vitro experiments, was very high $(99 \%, n=5)$.

\section{Cadmium exposure}

For the time-course experiments, the isolated macrophagelike cells were exposed to $\mathrm{CdCl}_{2}(50 \mu \mathrm{M}$; Sigma-Aldrich Co., St Louis, MO, USA) or control solution (vehicle) during 6, 24 , and 48 hours. For the concentration-response experiments, the cells were exposed to $0,2.5,12.5,25,37.5$, and $50 \mu \mathrm{M}$ of $\mathrm{CdCl}_{2}$ during 24 hours only. All exposure experiments were performed in duplicate. After these in vitro experiments, the conditioned media were collected and frozen $\left(-80^{\circ} \mathrm{C}\right)$ for subsequent cytokine measurements.

\section{Molecular markers of inflammation Protein}

We quantified protein concentrations of interleukin (IL)-8/ CXCL8 and IL-6 in cell-free conditioned medium, supernatant from saliva, sputum, and BAL fluid samples utilizing in-house enzyme-linked immunosorbent assay (ELISA) methods, as previously described. ${ }^{18}$ Briefly, commercially available antibody pairs MAB208/MAB 206 and MAF208/MAF 206 (R\&D Systems, Inc., Minneapolis, MN, USA) were used to detect IL-8 (detection range: $12.5-6,400 \mathrm{pg} / \mathrm{mL}$ ) and IL-6 (detection range: $3-375 \mathrm{pg} / \mathrm{mL}$ ). An intra-assay variation $<10 \%$ was accepted for the duplicate samples. We also quantified protein concentrations of MMP-9 in cell-free supernatant in conditioned medium, saliva, sputum, BAL fluid, and serum samples utilizing a commercial ELISA kit (DouSet ELISA MMP-9 Kit; R\&D Systems, Inc.). The analyses of MMP-9 were performed according to the manufacturer's instructions, and an intra-assay variation $<10 \%$ was accepted for the duplicate samples.

\section{mRNA}

The cells collected from the BAL fluid were resuspended in Rosewell Park Memorial Institute cell medium supplemented with 5\% serum and then put into Petri dishes ( 2 million cells/ dish). After incubation ( 2 hours), the nonadherent cells and supernatants were discarded, and the adhered cells (macrophages) were prepared for mRNA analysis. Total mRNA was isolated by PureLink ${ }^{\mathrm{TM}}$ Micro-to-Midi Total RNA Purification System (Thermo Fisher Scientific). DNase I amplification grade was used to remove the genomic DNA
(Thermo Fisher Scientific). First-strand cDNA was synthesized (from $0.5 \mu \mathrm{g}$ of total mRNA), using QuantiTect ${ }^{\circledR}$ Reverse Transcription Kit (Qiagen NV, Venlo, the Netherlands). The ABI Power SYBR Green Master mix (Thermo Fisher Scientific) was used to perform the real-time polymerase chain reaction (PCR). All primers were purchased from Thermo Fisher Scientific. The widely used cDNA of glyceraldehyde-3-phosphate dehydrogenase was adopted as a house-keeping gene. One microliter of cDNA was used in each PCR volume $(25 \mu \mathrm{L})$ to identify the products of interest. Data were analyzed using 7500 Software v.2.0.1, and the results were then calculated and expressed as $2^{-\Delta \mathrm{Ct}}$.

\section{Statistical analyses}

Nonparametric statistics were applied. Results are thus presented as median with range, unless otherwise stated. Between-group comparisons were performed using the Kruskal-Wallis test followed by Mann-Whitney $U$-test as post hoc test when appropriate. The comparisons between different $\mathrm{CdCl}_{2}$ exposure concentrations were assessed by Friedman test and followed by Wilcoxon signed rank test as a post hoc test. Correlations were determined using Spearman rank correlation. We utilized the STATISTICA software program version 12 (StatSoft Scandinavia AB, Uppsala, Sweden), and a $P$-value of $<0.05$ was considered statistically significant. $\mathrm{n}$ refers to the number of independent observations.

\section{Results}

\section{In vivo samples}

Clinical characteristics

The subjects in the COPD group were somewhat older than subjects in the other two groups, but the other parameters were well matched (Table 1). The spirometry volumes FVC and $\mathrm{FEV}_{1}$ were lower in smokers with COPD compared with healthy nonsmokers, and $\mathrm{FEV}_{1}$ was lower in smokers with COPD than in those without COPD, as a consequence of the inclusion criteria.

\section{Cadmium concentrations in cell-free BAL samples}

Smokers with or without COPD had markedly higher concentrations of cadmium in cell-free BAL fluid samples than did healthy, nonsmoking controls (Figure 1). However, there was no statistically significant difference between smokers with and without COPD, the two groups of longterm smokers. Cadmium concentrations below the LOD were, however, only found in healthy nonsmokers and in smokers with COPD, not in those without COPD. Palladium concentrations, which were measured in order to assess 


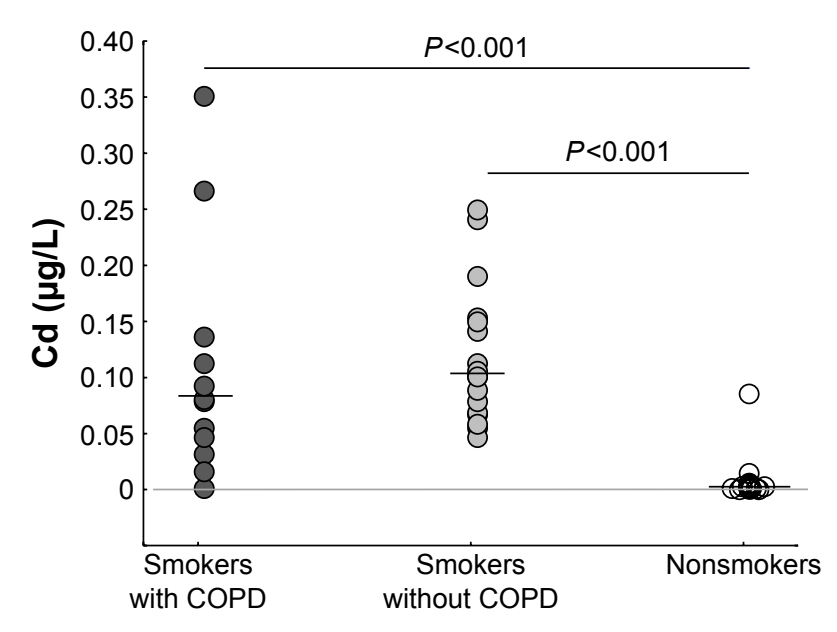

Figure I Concentrations $(\mu g / L)$ of cadmium (Cd) in cell-free BAL fluid samples from smokers with $(n=12)$ or without $(n=17)$ COPD compared with healthy nonsmokers $(n=19)$.

Notes: Data shown as median with individual values. $P$-values according to Mann-Whitney U-test.

Abbreviation: BAL, bronchoalveolar lavage.

vehicle particulate pollution background, were below the LOD for all samples, thereby indicating that the background exposure from traffic was modest for all groups.

A trend toward a sex difference in cadmium concentration in cell-free BAL fluid samples was observed when pooling subjects from all study groups (females: $0.085 \mu \mathrm{g} / \mathrm{L}$ [0.01-0.12] and males: $0.028 \mu \mathrm{g} / \mathrm{L}$ [0.006-0.09]), but this trend did not prove statistically significant $(P=0.09)$. A corresponding trend was observed when conducting the sex comparison analysis in the study groups of smokers with or without COPD separately (data not shown).

We observed no correlation between cadmium concentration in cell-free BAL fluid samples and age, smoking (pack-years and current smoking), or lung volumes (data not shown).

\section{Cadmium and inflammatory cells}

There were positive correlations between cadmium concentrations in cell-free BAL fluid samples and concentrations of neutrophils and $\mathrm{CD} 8^{+} \mathrm{T}$-lymphocytes in blood (Figure 2A and B).

\section{Cadmium and molecular markers of inflammation}

There were positive correlations between the concentrations of cadmium in cell-free BAL samples and mRNA for tumor necrosis factor (TNF)- $\alpha$ in BAL macrophages (Figure 3). This was also true for protein concentrations of IL-6, IL-8, and MMP-9 in cell-free sputum samples (Figure 4A-C). In general, these correlation coefficients tended to become higher when calculating correlations only in smokers with COPD (correlation coefficients and $P$-values are given in the figure legends).

\section{In vitro samples}

Exposure to $\mathrm{CdCl}_{2}$ caused a concentration-dependent increase of IL-8 protein concentrations in cell-free conditioned media from the macrophage-like cells cultured in vitro (Figure 5). Of note, MMP-9 protein concentrations were detectable in the same conditioned media, but there was no statistically significant effect of $\mathrm{CdCl}_{2}$ on these concentrations.

\section{Discussion}

In this study, we demonstrate measurable cadmium concentrations in cell-free BAL fluid samples from smokers
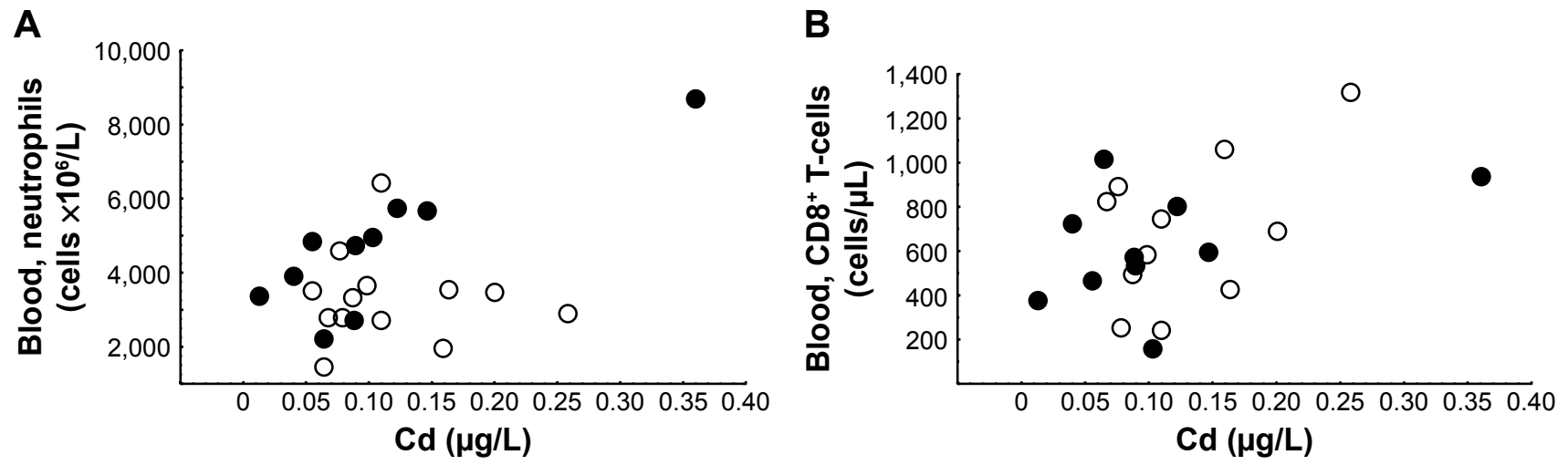

O Smokers without COPD Smokers with COPD

Figure 2 Relationship between cadmium (Cd) in the airways and inflammatory cells in blood.

Notes: Concentrations of $C d$ in cell-free $B A L$ fluid samples and $(A)$ neutrophils in blood (all smokers: $R=0.46, P=0.03, n=23$; smokers with $C O P D$ only: $R=0.86, P=0.00$, $\mathrm{n}=10$ ) and $(\mathbf{B}) \mathrm{CD} 8^{+}$T-cells in blood (all smokers: $R=0.44, P=0.04, \mathrm{n}=21$; smokers with COPD only: $R=0.41, P=0.24, \mathrm{n}=10$ ). All correlations analyzed with $S p e a r m a n$ rank correlation test.

Abbreviation: BAL, bronchoalveolar lavage. 


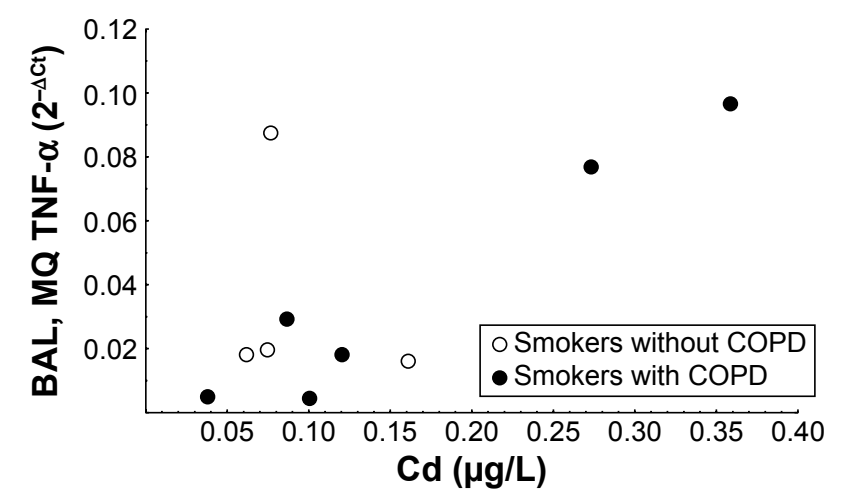

Figure 3 Relationship between cadmium (Cd) and messenger RNA for TNF- $\alpha$ in the airways.

Notes: Concentrations of $\mathrm{Cd}$ in cell-free BAL fluid and macrophage TNF- $\alpha$ at mRNA levels in BAL cells (all smokers: $R=0.60, P=0.03, n=10$; smokers with COPD only: $R=0.97, P=0.002, n=6$ ). All correlations analyzed with Spearman rank correlation test.

Abbreviations: BAL, bronchoalveolar lavage; MQ, macrophage; TNF- $\alpha$, tumor necrosis factor alpha. with or without COPD and show that these concentrations, in both groups, are markedly higher than those in healthy nonsmokers. We also show a positive correlation between enhanced cadmium concentrations in the cell-free BAL fluid samples from smokers regardless of COPD and several cellular or molecular markers of inflammation in the same human subjects. Finally, we demonstrate that $\mathrm{CdCl}_{2}$ stimulates the release of the archetype chemokine IL- 8 in human macrophage-like cells in vitro. Taken together, our findings illustrate the pathogenic potential of extracellular cadmium in the bronchoalveolar space of tobacco smokers in terms of disease involving innate effector cells.

To the best of our knowledge, our study is the first one to characterize cadmium concentrations in the extracellular compartment of the bronchoalveolar space in smokers with and

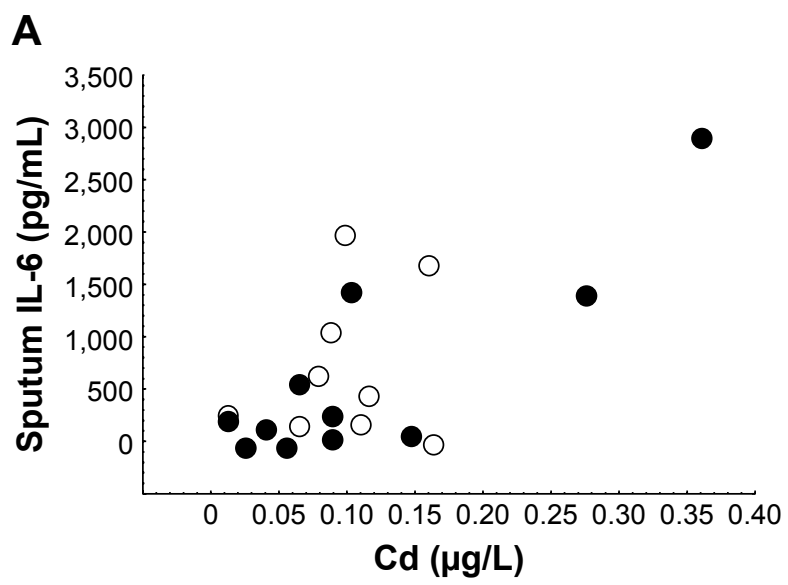

B
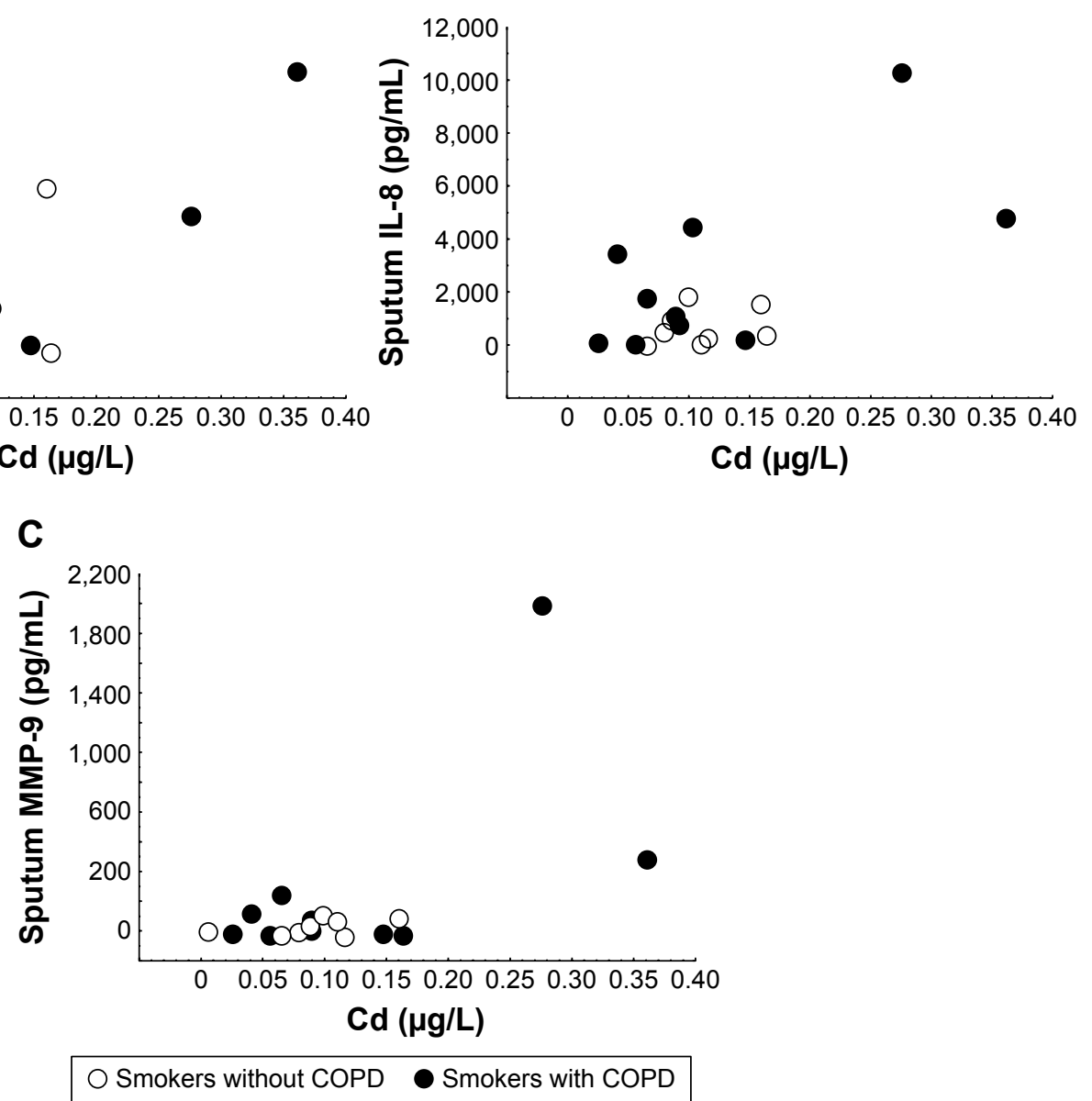

Figure 4 Relationship between cadmium (Cd) and molecular markers of inflammation in the airways.

Notes: Concentrations of $C d$ in cell-free $B A L$ fluid samples and $(\mathbf{A})$ IL-6 in sputum (all smokers: $R=0.69, P=0.00$ I, $\mathrm{n}=20$; smokers with $C O P D$ only: $R=0.86, P<0.00$ I, $\mathrm{n}=1 \mathrm{I}$ ) and (B) IL-8 in sputum (all smokers: $R=0.62, P=0.006, \mathrm{n}=18$; smokers with COPD only: $R=0.67, P=0.04, \mathrm{n}=10$ ) and (C) $\mathrm{MMP}-9$ in sputum (all smokers: $R=0.60, P=0.008, \mathrm{n}=18$; smokers with COPD only: $R=0.64, P=0.048, n=10)$. All correlations analyzed with Spearman rank correlation test.

Abbreviations: BAL, bronchoalveolar lavage; IL, interleukin. 


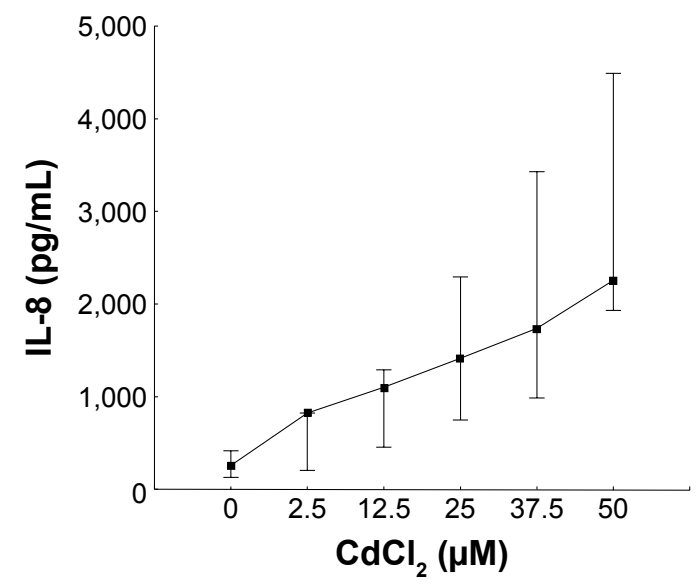

Figure 5 Effect of cadmium (Cd) on the archetype chemokine IL-8 in macrophagelike cells in vitro.

Notes: Concentrations of IL-8 (median with 25th-75th percentiles, pg/mL) after stimulation of derived macrophages from five different healthy nonsmokers by $\mathrm{CdCl}_{2}$. The induced increase in IL-8 concentrations correlated with the concentration of $\mathrm{CdCl}_{2}(\mu \mathrm{M})$ in a statistically significant manner $(R=0.57, P<0.00$ I, duplicate samples, five different donors). Correlation analyzed with Spearman rank correlation test.

Abbreviations: $\mathrm{CdCl}_{2}$, cadmium chloride; IL, interleukin.

without verified COPD, compared with healthy nonsmokers. However, compatible findings have previously been obtained in one single study on exhaled breath condensate. ${ }^{11}$ In that study, Mutti et al obtained evidence of higher concentrations of cadmium and other metals in the lungs of smokers with and without COPD, compared with healthy nonsmokers. ${ }^{11}$ Moreover, these cadmium concentrations in exhaled breath condensate correlated with the smoking history in a positive manner, suggesting that tobacco smoke really is the origin of cadmium in the lungs. In this respect, our cohort did not have sufficient statistical power to provide supportive information.

In our study, the history of tobacco smoking (ie, tobacco load) was very similar for smokers with and without COPD, an important aspect of the careful matching of smoking subjects in our study cohort. This "similarity" makes the fact that we detected no substantial difference in local cadmium concentration for smokers with and without COPD more conclusive. However, this lack of difference in extracellular cadmium concentration questions the role of cadmium in terms of being a direct cause of the chronic airway obstruction that separated our two groups of long-term smokers. We think that this lack of difference argues in favor of cadmium bearing pathogenic potential for the development of other aspects of disease in the airways of tobacco smokers.

Specifically, the finding of positive correlations with cellular markers of inflammation related to blood neutrophils and cytotoxic T-cells known to be involved in disease related to tobacco-smoking is indeed compatible with an involvement of cadmium in the disease process. ${ }^{11}$ Of note, the correlation between cadmium in BAL samples and neutrophils in blood was relatively strong, in particular for samples from smokers with COPD. Along these lines, the demonstrated correlations with molecular markers of inflammation included the archetype chemokine IL- 8 as well as IL-6 and MMP-9 in sputum samples. In further support of a mechanistic link between cadmium and neutrophils, the exposure of macrophage-like cells to $\mathrm{CdCl}_{2}$ caused a clearcut and concentration-dependent release of the archetype chemokine IL-8. Moreover, the strong correlation between extracellular cadmium concentrations in BAL samples and mRNA for TNF- $\alpha$ in macrophages from BAL samples adds further evidence of macrophages being targeted by cadmium from tobacco smoke. Collectively, these findings are all compatible with extracellular cadmium in the airways constituting a pathogenic factor involved in the mobilization of innate effector cells perpetuating other aspects of disease than that directly related to chronic airway obstruction.

It is difficult to judge to what extent the assessment of metals such as cadmium in a certain compartment is representative of the same metal in a different compartment. Mannino et al previously demonstrated that increased concentrations of cadmium in urine are significant predictors of impaired lung function in current and former smokers from a US normal population, but this was not the case in never-smokers from the same population. ${ }^{19}$ Basically, the same findings were obtained in a study of a South Korean population, and based upon these studies, it is not possible to conclusively judge how systemic and local cadmium concentrations in the peripheral airways (using BAL samples) relate to one another. ${ }^{20}$ Given that we lacked whole-blood and urine samples for the assessment of systemic cadmium concentrations in our current study cohort, this particular aspect remains of interest for future studies.

With reference to the trend toward higher cadmium concentrations in cell-free BAL fluid from female subjects in our current cohort, it is true that we were unable to prove this potential sex difference statistically significant. However, from a qualitative point of view, our results are compatible with previous publications suggesting that females have higher concentrations of cadmium in blood, urine, and kidney and that cadmium-related effects on health may be overrepresented among female subjects. ${ }^{21,22}$ Given that the previously postulated sex difference of cadmium in blood becomes less evident after menopause, our current results appear reasonable since smokers with COPD tend to be of higher age, as was the case of the females in our study cohort. 
Interestingly, Grasseschi et al previously forwarded evidence that alveolar macrophages constitute a prominent cadmium-containing cell type in the airways. ${ }^{23}$ In their study, it was revealed that smokers have a threefold increase in intracellular cadmium content in alveolar macrophages, compared with nonsmokers. However, in their study, the presence of COPD among smokers was not taken into account. Moreover, these investigators found that the cadmium content in alveolar macrophages correlated better with recent smoking history than with lifelong cumulative smoking history. Thus, either intracellular cadmium content in alveolar macrophages changes over shorter time periods or the limited life span of the macrophages sets a natural limit to the information obtained with that study approach. To us, the latter seems most feasible, given that cadmium has a very long biological half-life, 14-24 years in urine ${ }^{24}$ and 7-16 years in blood. ${ }^{25}$

Finally, we think that it is important to note that the postulated involvement of alveolar macrophages and neutrophils in the local response to extracellular cadmium in the bronchoalveolar space of smokers is supported by two previous publications based on animal models in vivo. ${ }^{12,13}$ In essence, these previous publications illustrate cadmiuminduced effects on the accumulation of innate effector cells and emphysema (in the rat model only), as well as effects on proteinase activity from MMP-2 and MMP-9, the latter likely to originate from innate effector cells. ${ }^{12,13}$

\section{Conclusion}

Our study on extracellular cadmium in the bronchoalveolar space of humans suggests that cadmium is markedly enhanced in the lungs of long-term smokers regardless of COPD. Moreover, our findings of several correlations with cellular and molecular markers of inflammation and, in one case, a direct effect on a key molecular marker of inflammation forward the mobilization of innate effector cells as an important action of cadmium in the airways. Clearly, this possibility deserves to be addressed in new and better-powered studies on tobacco smokers, where local cadmium concentrations can be related both to systemic cadmium and to additional parameters of specific pathology in the lungs, including the status of local host defense and the most common comorbidities among tobacco smokers.

\section{Acknowledgments}

We thank Karin Holm at Stockholm University for technical assistance with the analysis of metals in cell-free BAL fluid. We also thank Professor Carola Lidén and Doctor Hanna
Karlsson, Institute of Environmental Medicine, Karolinska Institutet, for their invaluable support throughout this study. The authors gratefully acknowledge the expert technical advice from Doctor Karlhans Fru Che regarding the experiments on macrophage-like cells in vitro. Project funding was obtained from the Swedish Research Council (LP and AL), the Swedish Heart-Lung Foundation (KL, LP, and AL), the Foundation for Rehabilitation and Medical Research in Gothenburg (FRF-stiftelsen; AL), Stockholm County Council (ALF-medel; AL), King Gustav V's and Queen Victoria's Freemason Research Fund (AL), and federal funding from Karolinska Institutet (LP and AL). No funding was obtained from the tobacco industry.

\section{Disclosure}

The authors report no conflicts of interest in this work.

\section{References}

1. O'Connor RJ, Li Q, Stephens WE, et al. Cigarettes sold in China: design, emissions and metals. Tob Control. 2010;19 Suppl 2:i47-i53.

2. Ajab H, Yaqub A, Mailk SA, Junaid M, Yasmeen S, Abdulla MA. Characterization of toxic metals in tobacco, tobacco smoke, and cigarette ash from selected imported and local brands in Pakistan. Scientific World Journal. 2014;2014:413614.

3. Uwakwe AA, Ibiam UA. Levels of cadmium in different brands of cigarettes sold in Abakaliki metropolis of Nigeria. Afr J Biochem Res. 2009;3:317-320.

4. Oberdorster G. Airborne cadmium and carcinogenesis of the respiratory tract. Scand J Work Environ Health. 1986;12:523-537.

5. Bernhard D, Rossmann A, Wick G. Metals in cigarette smoke. Life. 2005;57:805-809.

6. Hirst RN Jr, Perry HM Jr, Cruz MG, Pierce JA. Elevated cadmium concentration in emphysematous lungs. Am Rev Respir Dis. 1973;108: 30-39.

7. Pappas RS. Toxic elements in tobacco and in cigarette smoke: inflammation and sensitization. Metallomics. 2011;3:1181-1198.

8. Kollmeier H, Seemann J, Wittig P, Rothe G, Müller KM. Cadmium in human lung tissue. Int Arch Occup Environ Heath. 1990;62: 373-377.

9. Zhang L, Lv J, Sun S. Elements in lung tissues of patients from a high lung cancer incidence area of China. Biol Trace Elem Res. 2012; 148:7-10.

10. Bargagli E, Monaci F, Bianchi N, Bucci C, Rottoli P. Analysis of trace elements in bronchoalveolar lavage of patients with diffuse lung diseases. Biol Trace Elem Res. 2008;124:225-235.

11. Mutti A, Corradi M, Goldoni M, Vettori MV, Bernard A, Apostoli P. Exhaled metallic elements and serum pneumoproteins in asymptomatic smokers and patients with COPD or asthma. Chest. 2006; 129:1288-1297.

12. Bolognin M, Kirschvink N, Leemans J, et al. Characterisation of the acute and reversible airway inflammation induced by cadmium chloride inhalation in healthy dogs and evaluation of the effects of salbutamol and prednisolone. Vet J. 2009;179:443-450.

13. Kirschvink N, Vincke G, Fiévez L, et al. Repeated cadmium nebulizations induce pulmonary MMP-2 and MMP-9 production and emphysema in rats. Toxicology. 2005;211:36-48.

14. von Scheele I, Larsson K, Dahlén B, et al. Toll-like receptor expression in smokers with and without COPD. Respir Med. 2011;105:1222-1230.

15. Bergstrom J, Cederlund K, Dahlen B, et al. Dental health in smokers with and without COPD. PLoS One. 2013;8:e59492. 
16. Ji J, von Schéele I, Bergström J, et al. Compartment differences of inflammatory activity in chronic obstructive pulmonary disease. Respir Res. 2014;15:104.

17. Wilkinson KE, Palmberg L, Witasp E, et al. Solution-engineered palladium nanoparticles: model for health effect studies of automotive particulate pollution. ACS Nano. 2011;5:5312-5324.

18. Larsson K, Tornling G, Gavhed D, Müller-Suur C, Palmberg L. Inhalation of cold air increases the number of inflammatory cells in the lungs in healthy subjects. Eur Respir J. 1998;12:825-830.

19. Mannino DM, Holguin F, Greves HM, Savage-Brown A, Stock AL, Jones RL. Urinary cadmium levels predict lower lung function in current and former smokers: data from the Third National Health and Nutrition Examination Survey. Thorax. 2004;59:194-198.

20. Leem AY, Kim SK, Chang J, et al. Relationship between blood levels of heavy metals and lung function based on the Korean National Health and Nutrition Examination Survey IV-V. Int J Chron Obstruct Pulmon Dis. 2015;10:1559-1570.
21. Vahter M, Berglund M, Akesson A, Liden C. Metals and women's health. Environ Res. 2002;88:145-155.

22. Vahter M, Akesson A, Lidén C, Ceccatelli S, Berglund M. Gender differences in the disposition and toxicity of metals. Environ Res. 2007; 104:85-95.

23. Grasseschi RM, Ramaswamy RB, Levine DJ, Klaassen CD, Wesselius LJ. Cadmium accumulation and detoxification by alveolar macrophages of cigarette smokers. Chest. 2003;124:1924-1928.

24. Suwazono Y, Kido T, Nakagawa H, et al. Biological half-life of cadmium in the urine of inhabitants after cessation of cadmium exposure. Biomarkers. 2009;14:77-81.

25. Järup L, Rogenfelt A, Elinder CG, Nogawa K, Kjellstrom T. Biological half-time of cadmium in the blood of workers after cessation of exposure. Scand J Work Environ Health. 1983;9:327-331.
International Journal of COPD

\section{Publish your work in this journal}

The International Journal of COPD is an international, peer-reviewed journal of therapeutics and pharmacology focusing on concise rapid reporting of clinical studies and reviews in COPD. Special focus is given to the pathophysiological processes underlying the disease, intervention programs, patient focused education, and self management protocols.

\section{Dovepress}

This journal is indexed on PubMed Central, MedLine and CAS. The manuscript management system is completely online and includes a very quick and fair peer-review system, which is all easy to use. Visit http://www.dovepress.com/testimonials.php to read real quotes from published authors.

Submit your manuscript here: http://www.dovepress.com/international-journal-of-chronic-obstructive-pulmonary-disease-journal 